
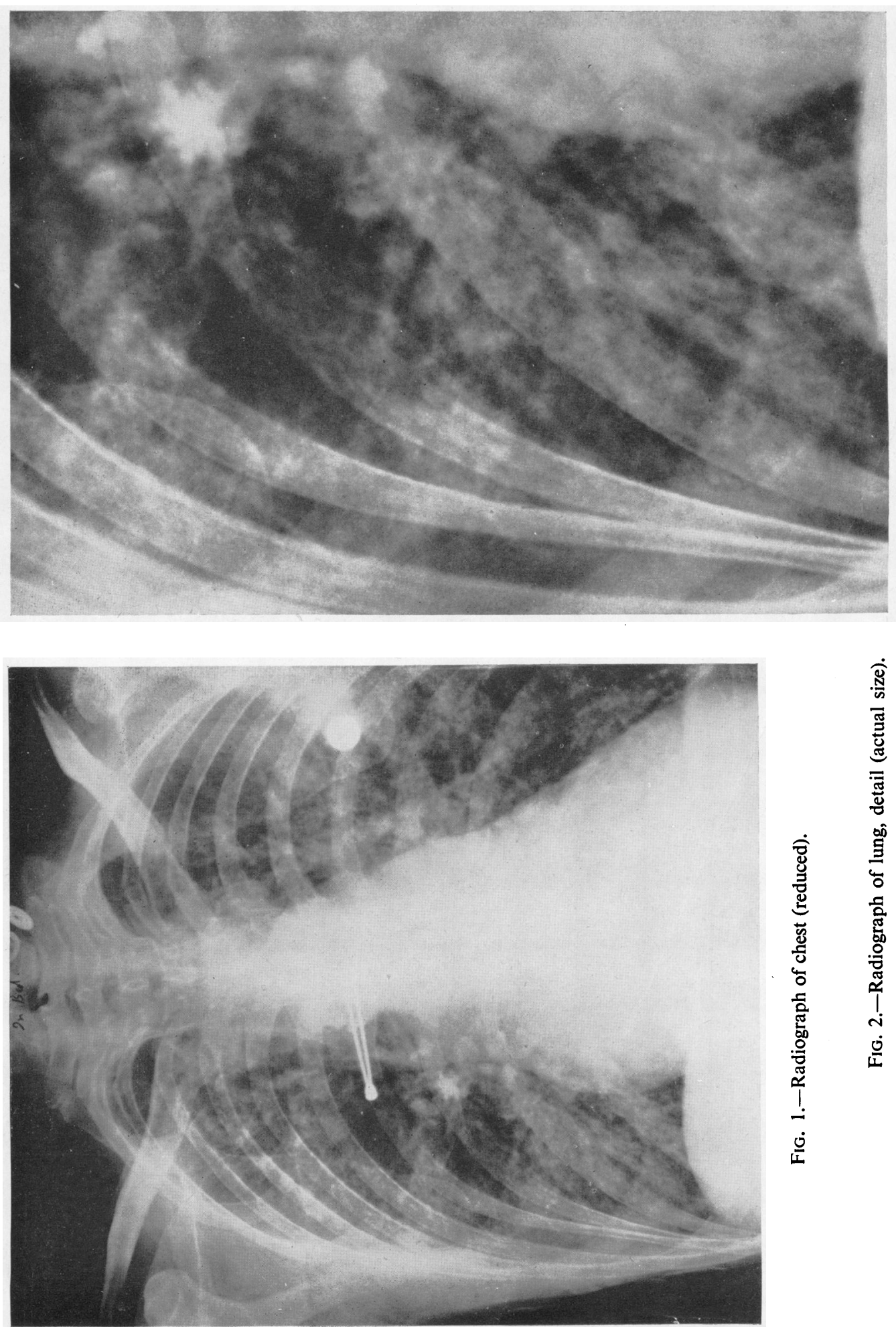


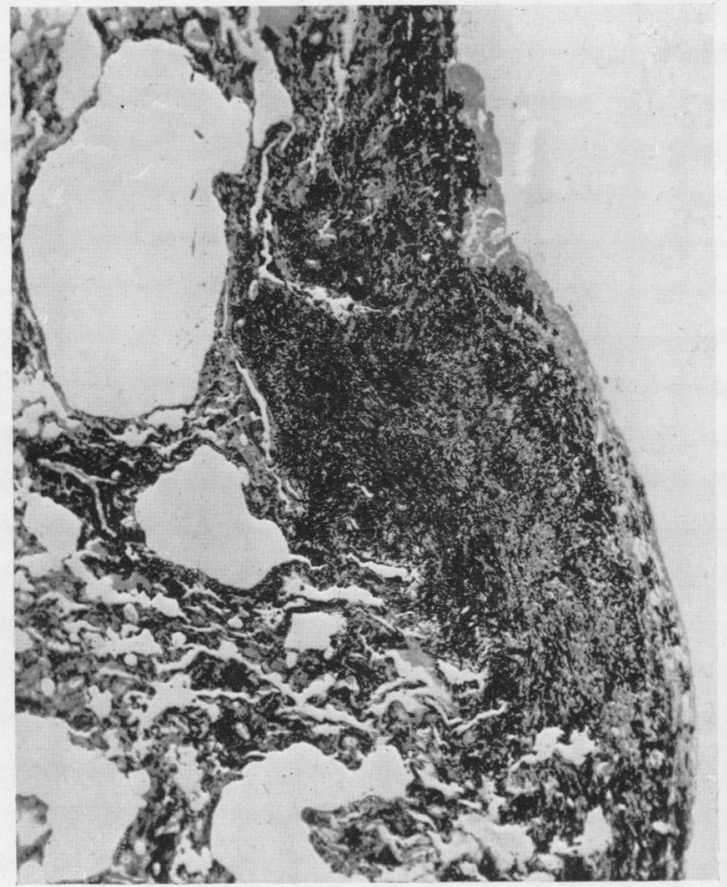

FIG. 3.-Subpleural nodule of fibrosis and underlying emphysema. Weigert's elastin stain and van Gieson. ( $\times 29$.

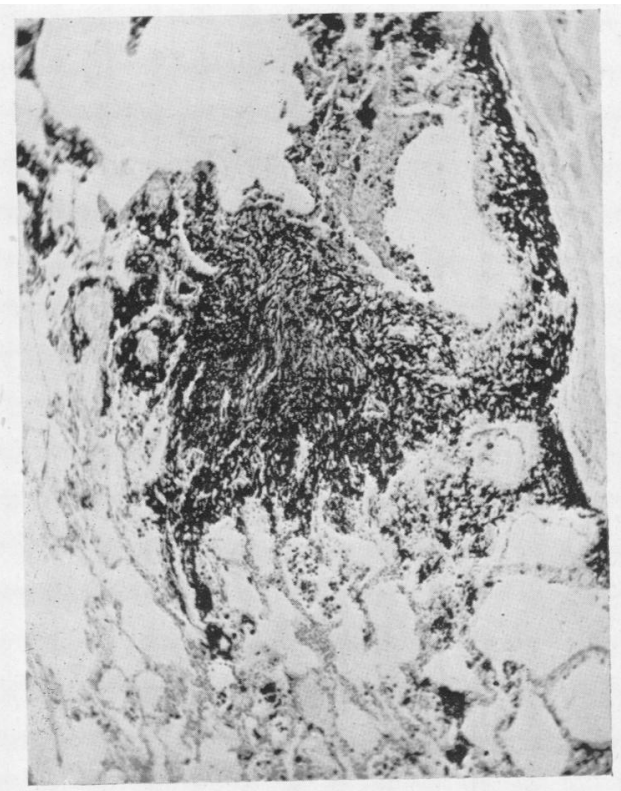

Fig. 5-Pigmented fibrous nodule: intraalveolar phagocytes : emphysema. Haematoxylin and eosin. $(\times 36$.

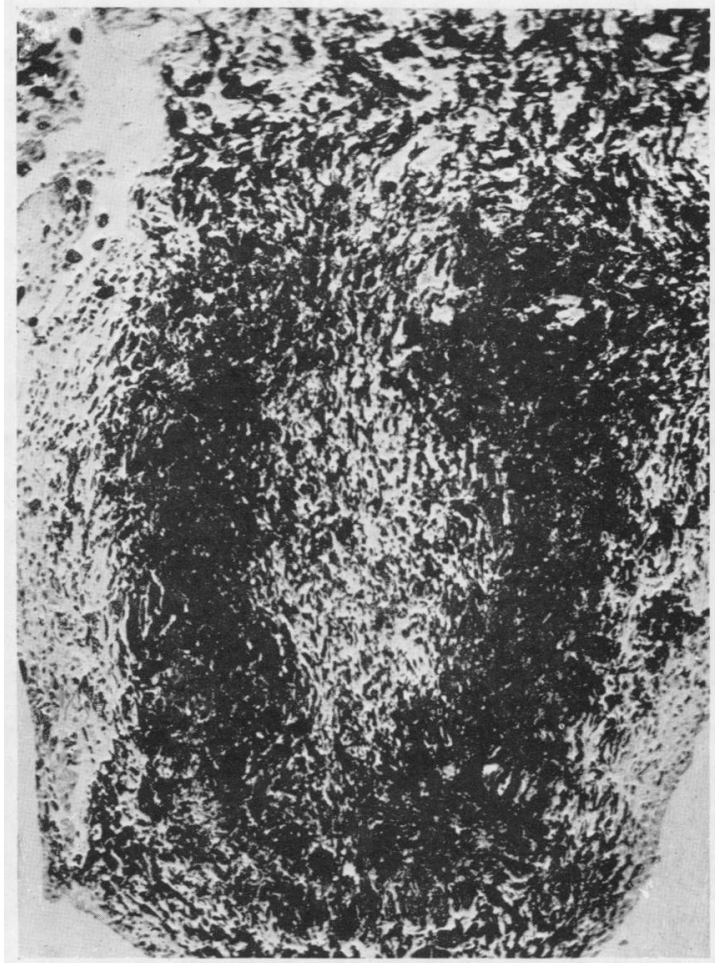

Fig. 4.- - Linear and circumferential fibrosis in pigmented nodule. Haematoxylin and eosin. $(\times 86$.

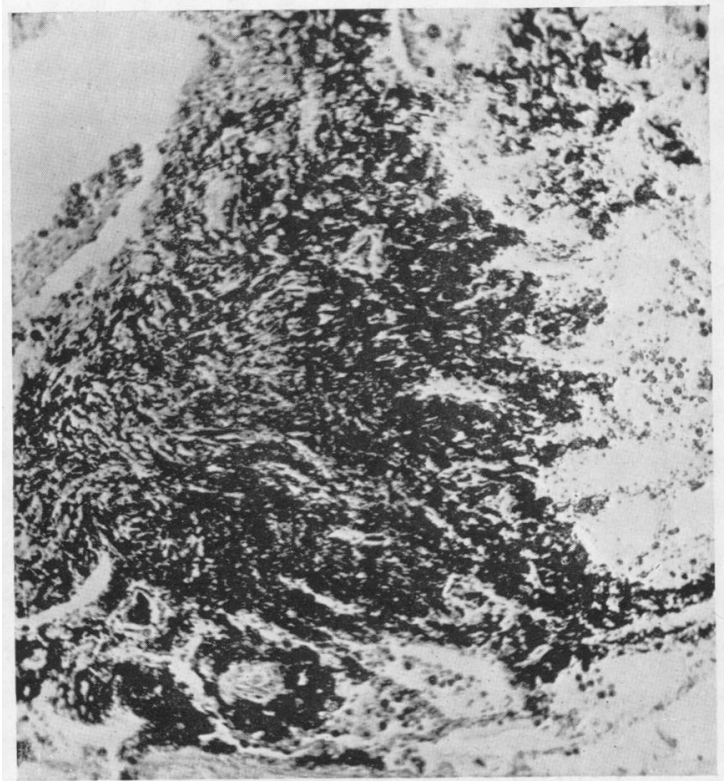

FIG. 6.-Higher magnification of fig. 5. Linear and radial fibrosis. $(\times 70$. $)$ 
Brit. J. industr. Med., 1947, 4, 100.

\title{
PNEUMOCONIOSIS IN A BOILER SCALER
}

\author{
BY \\ H. E. HARDING, D. L. MCRAE TOD, AND A. I. G. McLAUGHLIN \\ From Sheffield University, Anlaby Road Hospital, Hull, and the Factory Department, \\ Ministry of Labour and National Service
}

(RECEIVED FOR PUBLICATION, OCTOBER 17, 1946)

In 1944 we reviewed the scanty literature on lung disease in boiler scalers, and gave an account of the clinical, radiological, and pathological features of the lungs of such a worker. Since then Dunner and Hermon (1944) have reported the radiographical appearances in the lungs of five boiler scalers; four of these showed reticulation, and three also had tuberculosis; the fifth was the case already recorded by us. Channell (1945) noted that dust was produced in large quantities during the cleaning of boilers, and considered that masks were essential to protect the workers. He also stated that the incidence of upper respiratory infections appeared to be higher in personnel engaged in boiler cleaning than in other naval ratings.

Cook, Kemp, and Wilson (1945) radiographed the chests of nine cleaners of Stirling and Lancashire boilers at a railway works, and found little radiological evidence of pulmonary damage. The occupational histories showed that one man was engaged on the job for twenty-five years, and the others for lesser periods down to twenty-one months; four had had long spells out of the occupation. These authors are careful to note that their report covers the conditions only as they existed at the railway works concerned, but they also state that 'while there is no doubt that boiler cleaning is an unpleasant occupation, it does not necessarily induce ill health.' Analyses of flue dust and boiler scale showed that the total silica content of the former was always higher than that of the latter, and suggested that flue cleaning is likely to be more dangerous than boiler scaling.

\section{Case History}

A boiler scaler died on Feb. 8, 1946, at the age of 44 years. He had been employed for twenty-eight years as a whole-time scaler of marine boilers, and had done no other work. He had given up boiler scaling in 1943 on account of his cough and dyspnoea.

He was taken ill acutely on Jan. 21, 1946, with cough, dyspnoea, and profuse sputum. His doctor treated him with one of the sulphonamide drugs, but his condition deteriorated and he was admitted to hospital on Feb. 4. He was thin and very cyanosed; there was slight clubbing of the fingers, and slight oedema of the ankles; his respiration rate varied (average, about 40), but his temperature was not raised. A radiograph (figs. 1 and 2) was taken on Feb. 7: it shows reticulated shadows closely distributed over most of both lung fields, the apices alone being clear. Over the lower zones, particularly on the left side, there are in addition nodular shadows, some of the nodules being sharply defined. Calcified nodes are present in the region of the right hilum. The radiological picture as a whole may be classified as one of reticulo-nodulation. Treatment in hospital included penicillin, but he died four days after admission. A post-mortem examination performed the same day showed the presence of bronchopneumonia with oedema of the lungs and pneumoconiosis. The remainder of the body showed only the effect of heart failure.

Laboratory Investigations.-After fixation, both lungs showed tags of old adhesions posteriorly, and there was a slightly general thickening of the bluish-black pleura. There was marked pigmentation of the lungs, the black pigment tending to be in small aggregates or nodules surrounded by small areas of emphysematous lung. These pigmented nodules were not clearly palpable. There was slight bronchiectasis in the right upper lobe, and ill-defined patchy pneumonic consolidation in the lower lobes. The rather large heart showed some hypertrophy of the wall of the left ventricle, and marked hypertrophy of the right ventricle, the wall of which was $10 \mathrm{~mm}$. thick. There was no valvular abnormality.

Sections from the lungs showed marked black pigmentation (fig. 5) in all areas, some of it within the alveoli, some within phagocytes in the alveolar walls, and much in aggregates along the bronchi and beneath the pleura. There was no silicotic nodulation, but many of the 
nodular aggregates of pigment showed collagenous proliferation (figs. 3 to 6 ) as well as a marked increase of reticulin fibrils. The collagenous fibrosis tended to be radial or linear rather than whorled. Most of the black pigment was apparently carbon, since it was not visible in incinerated sections, which showed a moderate amount of iron pigment but less than had been expected. Examination of incinerated and acid-treated sections with polarized light showed a dusting of silica particles throughout the nodules, but again in lesser amounts than had been anticipated.

Chemical examination of adequate samples from the whole lung showed a fairly low ash -2.55 per cent. of dry lung. Iron formed $\mathbf{0 . 4 0}$ per cent. of the dry lung (i.e. almost twice the normal maximum given by Sheldon, 1935), the total silica content was 0.20 per cent., and the free silica, determined by the method of Trostel and Wynne (1940), was 0.13 per cent. of the dry weight.

\section{Discussion}

This man had spent most of his working life as a scaler of trawler boilers, and had given up this work at the early age of 42 because of his respiratory disability. Radiography was done only shortly before his death, and some of the shadows revealed may have been due to his circulatory failure. Much of the radiological appearance was, however, the result of pneumoconiosis. His lungs show much less pathological change than those previously reported, but there is a type of nodular fibrosis which is perhaps best described as 'reticulation', although it shows more than is implied by this term. Around each pigmented nodule is an area of emphysema, a feature found to be very common in many forms of pneumoconiosis. These emphysematous areas amount in the aggregate to a large proportion of the lung, and were doubtless in large measure responsible for the patient's shortness of breath, and for the hypertrophy of the right side of his heart.

In this instance we have not analysed samples of the boiler scale from a trawler. Analysis of a sample of such scale and of flue dust was recorded in our previous paper, and showed that there was 8.6 per cent. total silica in the scale and 6.1 per cent. in the flue dust: the percentages of iron were 10.1 and 48.3 respectively. As we pointed out then, there are wide variations in analyses of scale and flue from one ship to another according to the water used in the boilers and the fuel used to fire them. In some boiler scales there is a high percentage (up to 30) of zinc, arising from the use of zinc plates in the boilers to prevent corrosion of the tubes. Channell (1945) reported a high percentage of metallic copper and small amounts of metallic oxides, notably lead, and we know of the presence of other metals. From the water will come such constituents as salts of calcium, magnesium, potassium, and sodium. In brief, the point we wish to make is that boiler scalers are exposed to the inhalation of mixed dusts which contain silica (combined and free) in varying amounts. The percentages of free silica are low compared with those usually found in the industries accepted as having a silicosis risk.

Our first case (1944) had undoubted silicosis, and the one now reported had a pneumoconiosis which did not show the classical histological appearances of silicosis. It is possible that the fibrosis found in this man's lung represented a modified or atypical form of silicosis. Experimental work (Gardner 1938; Langelez, 1946) has shown that mixed dusts containing silica may produce retarded and modified or anomalous types of fibrosis in the tissues of animals.

\section{Summary}

Some of the clinical, radiographical, and pathological features of the lungs of a boiler scaler are described. The patient suffered from increasing dyspnoea, which made it necessary for him to give up his work at the age of 42 years. He died three years later from a chest illness, one of the elements of which was a superadded bronchopneumonia. Pathological investigation showed that he had contracted a form of pneumoconiosis in which typical silicotic nodules were not found. The lesions consisted of pigmented nodules, each with a surrounding zone of emphysema, and were associated with collagenous fibrosis of linear or radial distribution, in addition to marked increase of reticulin fibrils. There was no sign of tuberculosis. The radiograph showed reticulo-nodulation.

The photomicrographs were taken by Mr. A.W. Collins, F.I.M.L.T

\section{REFERENCES} Channell, G. D. (1945). J. roy. Naval med. Serv., 31, 146. $58,123$.

Dunner, L., and Hermon, R. (1944). Brit. J. Radiol., 17, 355.

Gardner, L. U. (1938). In Lanza, A. J., Silicosis and Asbestosis, New York, p. 286.

Harding, H. E., McRae Tod, D. L., and McLaughlin, A. I. G. (1944). Brit. J. industr. Med., 1, 247.

Langelez, A. (1946). La Silicose, Liège. p. 113.

Sheldon, J. H. (1935). Haemochromatosis. London. p. 211. Trostel, L. J., and Wynne, D. J. (1940). Amer. ceramic Soc. J.. 23, 18 .

For Illustrations of this Article, see pages 98 and 99. 